\title{
Persistência do trabalho infantil ou da exploração do trabalho infantil
}

\author{
Persistence of child labor or exploration of child labor
}

\section{Persistencia del trabajo infantil la exploración del trabajo infantil}

\author{
Soraya Franzoni Conde \\ Universidade Federal de Santa Catarina, Programa de Pós-graduação em Educação, \\ Professora permanente. \\ http://orcid.org/0000-0002-5271-6479 \\ Mauricio Silva \\ Universidade Federal de Santa Catarina, Professor aposentado. \\ https://orcid.org/0000-0003-0292-8366
}

\begin{abstract}
Resumo: 0 artigo visou problematizar as relações entre o processo de formação humana da infância da classe trabalhadora e a problemática da "exploração do trabalho infantil", por sua vez tão envolta em mitos, polêmicas e equívocos, objeto de um certo senso comum por parte da academia, de instituições não governamentais e órgãos oficiais, da mídia e da população em geral. Nesse sentido, o enunciado do artigo objetiva trazer à discussão elementos teórico-conceituais acerca da problemática em questão, nos quais ganha centralidade a pergunta-síntese/pergunta-problema: "trabalho infantil ou exploração do trabalho infantile", circunscrita à perspectiva histórica do sistema capitalista de produção. Tanto a literatura acadêmica quanto os documentos e dados oficiais e mesmo os não governamentais (terceiro setor) privilegiam a expressão "trabalho infantil", ao invés de "exploração do trabalho infantil". Nesse viés, a ideia é, do ponto de vista metodológico, refletir a partir da literatura existente e dos dados estatísticos. Entendemos que o escamoteamento da palavra "exploração" é parte da estratégia política e discursiva que busca desviar o foco social do elemento central da sociedade capitalista: a exploração da mais-valia. Desse modo, podemos afirmar que confusões conceituais, etimológicas, epistemológicas e ideológicas a respeito do tema são parte do jogo discursivo político-ideológico aparente e, tratando de aspectos superficiais do problema, contribuem para o enfraquecimento da luta por outra sociedade,
\end{abstract}

Doutora em Educação pela Universidade Federal de Santa Catarina; Mestre em Sociologia Poĺtica pela Universidade Federal de Santa Catarina.

Agradecemos à Fapesc pelo financiamento recebido para desenvolvimento da pesquisa que culmina nesse artigo, conforme Edital 06/2016 - Jovens Pesquisadores T0 2017 TR 1774

2 Doutor em Educação pela Universidade de Campinas; Mestre em Ciências do Esporte e Pedagogia do Esporte pela Universidade Johan Wolfgang Göthe Universiutät, Frankfurt, Alemanha. 
persistindo o problema diante das contradições e crises insolúveis do capital, que têm na miséria oriunda da exploração do trabalho o elemento central de sua produção/reprodução.

Palavras-chave: Trabalho. Educação. Infância. Trabalho infantil. Exploração.

Abstract: The article aimed to problematize the relations between the process of human formation of the working class childhood and the problem of the "exploitation of child labor", in turn so wrapped up in myths, controversies and misconceptions, object of a certain common sense by the researchers, non-governmental institutions and official bodies, the media and the general population. In this sense, the wording of the article aims to bring to the discussion theoretical and conceptual elements about the problem in question, in which the synthesis question/problem-question: "child labor or exploitation of child labor?", Circumscribed in the historical perspective of the capitalist system of production. Both academic literature and official and even non-governmental (third sector) documents and data privilege the term "child labor" rather than "exploitation of child labor". From this point of view, the idea is, from a methodological point of view, to reflect from the existing literature and statistical data. We understand that the concealment of the word "exploitation" is part of the political and discursive strategy that seeks to divert the social focus from the central element of capitalist society: the exploitation of surplus value. Thus, we can say that conceptual, etymological, epistemological and ideological confusions about the theme are part of the apparent political-ideological discursive game and, dealing with superficial aspects of the problem, contribute to the weakening of the struggle for another society, persisting the problem before of the insoluble contradictions and crises of capital, which has the central element of its production / reproduction in the misery arising from the exploitation of labor.

Keyboards: Work. Education. Childhood. Exploration.

Resumen: El artículo ha pretendido problematizar las relaciones entre el proceso de formación humana de la infancia de la clase trabajadora y el problema de la "explotación del trabajo infantil", a su vez envuelto en mitos, controversias y conceptos erróneos, objeto de un cierto sentido común por parte de la academia, instituciones no gubernamentales y organismos oficiales, los medios de comunicación y la población en general. En este sentido, la redacción del artículo tiene como objetivo traer a la discusión elementos teóricos y conceptuales sobre el problema en cuestión, en el que la pregunta de síntesis/ problema-pregunta: "żtrabajo infantil o explotación del trabajo infantile", circunscrito a la perspectiva histórica del tema. sistema de producción capitalista. Tanto la literatura académica como los documentos y datos oficiales e incluso no gubernamentales (tercer sector) privilegian el término "trabajo infantil" en lugar de "explotación del trabajo infantil". Desde este punto de vista, la idea es, desde un punto de vista metodológico, reflexionar a partir de la literatura existente y los datos estadísticos. Entendemos que el ocultamiento de la palabra "explotación" es parte de la estrategia política y discursiva que busca desviar el enfoque social del elemento central de la sociedad capitalista: la explotación de la plusvalía. Por lo tanto, podemos decir que las confusiones conceptuales, etimológicas, epistemológicas e ideológicas sobre el tema son parte del aparente juego discursivo político-ideológico $y$, al abordar aspectos superficiales del problema, contribuyen al debilitamiento de la lucha por otra sociedad, persistiendo el 
problema antes de las contradicciones y crisis insolubles del capital, que tiene el elemento central de su producción/reproducción en la miseria que surge de la explotación del trabajo.

Palabras clave: Trabajo. Educación. Infancia. Exploración.

Recebido em 10 de setembro de 2019

Aceito em 16 de abril de 2020

Publicado em 05 de junho de 2020

\section{INTRODUÇÃO}

0 artigo tem como escopo problematizar as relações entre o processo de formação humana da infância da classe trabalhadora, cuja vida cotidiana está secularmente imersa no âmbito da problemática da "exploração do trabalho infantil". Nesse sentido, o enunciado deste artigo tem como objetivo principal trazer para o debate elementos teóricoconceituais acerca da problemática em questão. Busca contribuir para o debate sobre a pergunta-síntese/pergunta-problema que subjaz ao título formulado: "trabalho infantil ou exploração do trabalho infantil?".

Essa indagação é recorrente na perspectiva das contradições do capital e suas crises, que engendram, por meio da acumulação de capital e da propriedade privada dos meios de produção, a exploração dos trabalhadores adultos e das crianças desde o século XIX e a "persistência" da exploração do trabalho infantil até os dias atuais, no âmbito do neoliberalismo. Tanto a literatura acadêmica quanto os documentos oficiais do governo (dados estatísticos) e os não governamentais (terceiro setor) privilegiam a expressão "trabalho infantil", ao invés de "exploração do trabalho infantil". 3 Vale destacar que a hipótese que subjaz à pergunta-síntese é que "não é possivel erradicar a exploração do trabalho infantil no âmbito do processo histórico da exploração capitalista."

Metodologicamente, este ensaio teórico busca fazer reflexões a partir da literatura existente e dos dados estatísticos. 0 intuito é abordar também as possíveis confusões conceituais, etimológicas, epistemológicas e ideológicas, visando, além disso, contribuir para o debate na academia e, principalmente, nos processos de formação inicial e continuada de professores, em movimentos sociais e sindicais, famílias, gestores, formadores e, por fim, para a formação crítica das crianças e dos jovens sobre esse fenômeno histórico que sobre eles incide.

\footnotetext{
3 Este artigo contém alguns parágrafos, citados na íntegra ou modificados parcialmente no conteúdo, em dois artigos dos autores cuja referência foi aqui ocultada para garantir anonimato.
} 
A rigor, a problemática do trabalho infantil, ou melhor, a exploração do trabalho infantil, é assunto muito complexo, carregado de mitos e equívocos. No geral, a sociedade coloca o trabalho infantil de forma anistórica e desconectada do problema da exploração humana, como algo cultural e virtuoso por parte das populações empobrecidas. É lugarcomum frases apologetas sobre o trabalho infantil como algo que enobrece e dignifica as crianças desde pequenas. Não sem razão, tal apologia é sempre destinada às crianças pobres, cujo trabalho precoce é uma necessidade de sobrevivência, evidenciando um recorte de classe. Não é comum encontrarmos latifundiários, grandes empresários ou trabalhadores de alto salário indicando o trabalho como uma solução enobrecedora à educação de seus filhos, o que costuma ocorrer nas mais caras escolas e cursos extracurriculares.

De acordo com esse enunciado, trataremos da persistência do trabalho infantil no Brasil. Para isso, recorremos às origens históricas do problema, à especificidade do modo capitalista de produção e aos dados atuais. Entendemos que revelar a centralidade da categoria exploração é fundamental para compreensão da mais-valia, misterioso segredo revelado por Marx no século XIX, n'O Capital.

Nesse sentido, é mister, na primeira parte deste artigo, delimitar quando o trabalho infantil deixa de ter um sentido apenas geral, como produtor de valores de uso, e torna-se um problema social pautado na produção de valor de troca e na exploração. Em seguida, na segunda parte, sob os fundamentos históricos desenvolvidos na primeira, desvelamos o problema central proposto por esse ensaio: trabalho infantil ou exploração do trabalho infantil? Qual o problema atual? Por último, a partir dos dados empíricos apresentados na terceira parte, ressaltamos a persistência do problema e sua impossibilidade de superação diante da lógica desigual e perversa da exploração da mais-valia na sociedade capitalista.

\section{SOBRE QUANDO O TRABALHO INFANTIL SE TORNA UM PROBLEMA SOCIAL}

\footnotetext{
Desta vala imunda a maior corrente da indústria humana flui para fertilizar o mundo todo. Deste esgoto imundo jorra ouro puro. Aqui a humanidade atinge o seu mais completo desenvolvimento e sua maior brutalidade, aqui a civilização faz milagres e o homem civilizado torna-se quase um selvagem. (TOCQUEVILLE, 1835 apud HOBSBAWM, 2007, p. 49).
}

Se é verdade que o trabalho não foi uma invenção do capitalismo, também o é que, na forma capitalista de produção, ele recebe outra conotação e consolida-se como um problema social combatido por meio de políticas e legislações que o proíbem. 0 final do século 
XVIII e o início do século XIX foram marcados por transformações políticas e econômicas que impulsionaram o advento da era industrial (HOBSBAWM, 2007).

Ao estudar os padrões e experiências da classe operária inglesa durante a Revolução Industrial, Thompson (2002) ratifica a ideia de que a inserção precoce no trabalho industrial é reflexo das determinações da vida familiar. As transformações no modo de vida dos trabalhadores resultaram na queda do padrão de vida da classe operária, no trabalho feminino e no trabalho infantil (CONDE, 2012). 0 autor evidencia, com base em dados, o aumento da taxa de mortalidade infantil na idade entre zero e cinco anos durante as primeiras décadas do século XIX. Tal constatação, relacionada às doenças, à subnutrição e às deformidades oriundas das novas ocupações, é assim relatada:

\begin{abstract}
Esta elevada taxa de mortalidade infantil entre os filhos de trabalhadores frequentemente citados como beneficiários da Revolução Industrial pode ser atribuida, em parte, às condições sanitárias do ambiente. Pode também estar associada a uma deformação típica - o estreitamento da ossatura pélvica - das meninas que trabalham na fábrica desde a infância, trazendo dificuldade para os partos, com a debilidade dos recém-nascidos cujas mães trabalhavam até a última semana de gravidez, e, acima de tudo, com a falta dos necessários cuidados com os recém-nascidos. [...] Mães muito jovens, que trabalhavam eventualmente na fábrica desde os oito ou nove anos, não tinham qualquer preparo doméstico; a ignorância médica era assustadora; os pais eram vítimas de superstições fatalistas (fomentadas, às vezes, pelas igrejas); os narcóticos, principalmente o láudano, eram utilizados para calar o bebê. (THOMPSON, 2002, p. 196-197).
\end{abstract}

As condições de vida e de trabalho eram degenerativas e acarretavam alta mortalidade e deformidades físicas entre os trabalhadores, tornando-os figuras facilmente identificadas na rua por suas pernas tortas, ombros projetados para frente e tortos, tornozelos inchados, peito de "pombo", entre outras deformações (CONDE, 2012). 0 mesmo ocorria às crianças da indústria algodoeira, que eram franzinas, doentes, frágeis e malvestidas. 0 trabalho nas fábricas condenava muitas meninas ao estreitamento da ossatura pélvica, que, por sua vez, gerava dificuldades para os partos. Além disso, como indica Thompson (2002), ocorria a utilização de narcóticos para acalmar bebês filhos(as) de trabalhadoras.

Entre 1780 e 1840, conforme laudos médicos, relatórios de inspeção e estudos examinados pelo autor, a exploração de crianças aumentou de maneira considerável, principalmente nos campos carboniferos, nas olarias, nas cozinhas, nas operações em portinholas de ventilação e nas fábricas. Os conflitos entre classes sociais antagônicas já se estabeleciam de maneira incisiva. De um lado, os movimentos de trabalhadores e os relatórios médicos e de inspeção de fábricas denunciavam a mortalidade infantil e as 
péssimas condições de vida e de trabalho nas fábricas; de outro, os arautos do liberalismo responsabilizavam as familias pela exploração do trabalho infantil (CONDE, 2012).

Descartando a naturalidade do trabalho realizado na grande indústria, Thompson (2002) afirma que, embora não seja algo novo, o trabalho infantil adquire uma nova conotação com a exploração da mais-valia. 0 autor considera que a criança foi parte intrínseca da economia familiar e agrícola anterior a 1780 e que certas atividades, como limpar chaminés e trabalhar em navios, desempenhadas por crianças pobres e órfãs antes da Revolução Industrial, eram piores do que muitas funções na fábrica. Entretanto, ressalta o historiador, esses fatos isolados não eram destinados à exploração de mais-valia nem predominantes: "[...] a forma predominante de trabalho infantil era a doméstica ou a praticada no seio da economia familiar. As crianças que mal sabiam andar podiam ser incumbidas de apanhar e carregar coisas." (THOMPSON, 2002, p. 203).

Carregar algodão na peneira, estender o algodão solto, girar manivelas, limpar o domicílio, preparar pão e cerveja são relatados pelo autor como exemplos de trabalhos infantis realizados antes da exploração de crianças para a produção de mais-valia. Muitas familias tinham interesse nas atividades que complementavam seus rendimentos com a ajuda da criança. Mas, em comparação ao trabalho industrial, as atividades domésticas eram mais variadas, e não havia prolongamento ininterrupto, mas um ciclo de tarefas. A introdução era gradual e respeitava as idades:

\footnotetext{
Nenhuma criança tinha que pisar sobre o algodão oito horas por dia, seis dias por semana. Em síntese, podemos supor que havia uma introdução gradual ao trabalho que respeitava a capacidade e a idade da criança, intercalando-o com entrega de mensagens, a colheita de amoras, a coleta de lenha e as brincadeiras. Acima de tudo, o trabalho era desempenhado nos limites da economia familiar, sob cuidado dos pais. (THOMPSON, 2002, p. 25).
}

Como podemos perceber, o autor ressalta que há diferenças significativas entre o trabalho infantil familiar anterior à Revolução Industrial, quando os ritmos e as atividades respeitavam a capacidade e o limite de idade da criança, intercalando suas ações com entregas de mensagens e coleta de frutos, e o trabalho desenvolvido nas indústrias do século XIX, com jornadas exaustivas, realizadas todos os dias da semana, e atividades repetitivas voltadas fundamentalmente à produção de mais-valia. 0 trabalho das crianças no âmbito familiar se destinava à produção de objetos para o uso e o consumo da família (valor de uso), e não, como ocorre no trabalho na grande indústria, para a produção de mercadorias a serem trocadas por dinheiro no mercado (valor de troca). 0 objetivo do trabalho deixou de 
ser a produção de valores de uso e passou a ser produção de valor de troca. Conforme Marx (2006, p. 18-19), são as relações sociais que determinam a forma que o trabalho assume:

[...] um negro é só um negro. Só em determinadas relações é que ele se torna um escravo. Uma máquina de fiar algodão é uma máquina para fiar algodão. Apenas em determinadas relações ela se torna capital. Arrancada a estas relações, ela é tão pouco capital como o ouro em si [.... Na produção, os homens não atuam só sobre a natureza, mas também uns sobre os outros. Produzem apenas atuando conjuntamente dum modo determinado e trocando suas atividades umas pelas outras. Para produzirem entram em determinadas relações uns com os outros, e só no seio destas relações sociais se efetua sua ação sobre a natureza, se efetua a produção. [...] As relações sociais em que os individuos produzem, as relações sociais de produção alteram-se, portanto, transformam-se com a alteração do desenvolvimento dos meios materiais de produção, as forças de produção. As relações de produção na sua totalidade formam aquilo a que se dá o nome de relações sociais, a sociedade, é na verdade, uma sociedade num estágio determinado, histórico, de desenvolvimento, uma sociedade com caráter peculiar, diferenciado. A sociedade antiga, a sociedade feudal, a sociedade burguesa são outras tantas totalidades de relações de produção, cada uma das quais designa, ao mesmo tempo, um estádio particular de desenvolvimento da história da humanidade. Também o capital é uma relação social de produção. É uma relação burguesa de produção, uma relação de produção da sociedade burguesa. 0s meios de subsistência, os instrumentos de trabalho, as matérias-primas de que se compõem o capital - não foram eles produzidos e acumulados em dadas condições sociais, em determinadas relações sociais? Não são eles empregues para uma nova produção em dadas condições sociais, em determinadas relações sociais? E não é precisamente este caráter social determinado que transforma em capital os produtos que servem para a nova produção?

Se são as relações sociais que determinam o trabalho e a forma com que os homens atuam uns sobre os outros, podemos afirmar que uma criança é só uma criança, e somente em determinadas relações sociais ela se torna uma trabalhadora. 0 trabalho também é só uma forma de produção da vida, e somente em determinadas relações ele deixa de ser meio de produção de valores de uso e passa, prioritariamente, a produzir mais-valia.

Ainda para reiterar que o problema da exploração do trabalho infantil, no caso específico deste estudo, ocorre no contexto do trabalho no capitalismo, ilustramo-lo com a citação de Marx (1978, p. 76):

Uma cantora que entoa como pássaro é um trabalhador improdutivo. Na medida em que vende seu canto, é assalariada ou comerciante. Mas, a mesma cantora, contratada por um empresário, que a faz cantar para ganhar dinheiro, é um trabalhador produtivo, já que produz diretamente capital. 
Para o autor, o capital não consiste somente em produzir meios de subsistência, instrumentos de trabalho e matérias-primas, mas em valores de troca, em relações e em grandezas sociais que parecem beneficiar o trabalhador, mas produzem a sua miséria. Marx (1978) define as características próprias da produção capitalista, a saber: 1) a produção capitalista não é só produção de mercadorias, embora no seu seio todos os produtos sejam mercadorias; 2) é, em primeiro lugar, produção de mais-valia, de capital, sob a vestimenta da mercadoria, desfrute do trabalho de outrem; 3) é produção e reprodução da relação capitalista e do trabalho assalariado em que a educação, a legislação e a religião assumem lugar destacado, sem as quais a produção de capital não é possível.

As três características esboçadas anteriormente estão, segundo o autor, relacionadas de maneira interdependente. A mercadoria, na sociedade capitalista, transformase em capital, ampliado por meio da relação de apropriação do excedente do trabalho humano e posterior troca por dinheiro. Como o trabalhador, sob o modo capitalista, no campo ou na cidade, não usa os meios (instrumentos, maquinaria, matéria-prima e força de trabalho) para a produção de valores de uso, mas para a produção de valores de troca, destinados à produção de mais-valia, toda a produção de mercadoria ocorre enviesada por essa finalidade. Dessa forma, a agricultura ou o trabalho artesanal, antes voltados à subsistência e à produção de valores de uso, transformam-se em produção para o comércio, cuja finalidade última é a troca por dinheiro. Na troca por dinheiro, o valor agregado ao produto é maior do que o valor pago ao trabalhador, gerando, assim, a mais-valia.

Destinada à troca para apropriação de mais-valia por outrem, a produção capitalista, que tem na parte não paga do trabalho a origem de sua acumulação, só se reproduz com a existência de uma classe crescente de trabalhadores que, destituída dos meios de produção, submeta-se a ser explorada por meio do trabalho assalariado. Quanto mais o trabalhador trabalha, mais riqueza ao capitalista gera. Quanto mais o trabalhador trabalha, mais desenvolve o processo de trabalho, que é convertido em tecnologias geradoras do desemprego. Quanto maior o número de desempregados, maior a possibilidade de os capitalistas encontrarem trabalhadores famintos capazes de se submeterem aos piores salários e de enviarem seus filhos ao trabalho produtivo. Assim, as formas de reprodução tornam-se as formas de produção do sistema (CONDE, 2012).

$\mathrm{Na}$ troca, a forma concreta e qualitativa da atividade individual é igualada a outras formas distintas e concretas de trabalho, compondo o que Marx (1978, 1988b) denomina de trabalho social abstrato. 0 trabalho de produção de tabaco, por exemplo, é igualado a outras formas concretas de trabalho na relação de troca mediada pelo dinheiro. 0 problema é que, por trás do dinheiro pago pelas mercadorias, encontram-se ocultados os salários e a produção da mais-valia. Essa equiparação, que torna equivalente o que é desigual, cria um 
nexo relacional unificado, transformando o trabalho privado em social e o trabalho concreto, em abstrato.

Segundo Marx (1988), o dispêndio de energia física é uma característica do trabalho, mas a especificidade humana traz duas constituições diferenciais: o pôr teleológico previsível e o caráter abstrato social típico do valor. Rubin (1987, p. 151), concordando com Marx (1988), afirma que o trabalho "[...] é um dispêndio de energia humana em forma fisiológica [...] entendido também como fenômeno social relacionado à determinada forma de produção." Já o trabalho abstrato vai além das formas concretas de dispêndio de energía física do trabalhador, compondo uma relação social mercantil de produtores separados:

\footnotetext{
0 conceito de trabalho abstrato é a abstração de formas concretas do trabalho, relação social básica entre produtores mercantis separados. 0 conceito de trabalho abstrato pressupõe uma determinada forma social de organização do trabalho numa economia mercantil: os produtores individuais de mercadorias não estão vinculados no próprio processo de produção, na medida em que esse processo representa a totalidade das atividades de trabalho concretas; este vínculo se realiza através do processo de troca, isto é, através da abstração dessas propriedades concretas. 0 trabalho abstrato não é uma categoria fisiológica, mas uma categoria social e histórica. (RUBIN, 1987, p. 159).
}

Conforme o autor, o trabalho coletivo abstrato torna os produtores individuais de mercadorias distantes no ato de produção, vinculados por meio da troca, na qual se abstrai das características individuais e concretas de cada trabalho. Na troca, não aparece quem produziu: adultos, crianças, mulheres, idosos ou deficientes. Entretanto, é pela troca que as formas concretas de produção da mercadoria se vinculam e compõem o trabalho social abstrato. Ou seja, a troca permite que os produtos do trabalho infantil se vinculem às mercadorias que circulam do outro lado do mundo.

É por essas características sociais, históricas e específicas, num determinado modo de produção da existência, que o trabalho infantil se torna um problema social generalizado e deixa de ser local para tornar-se global. Não se trata de um problema específico de um grupo cultural, mas do modo de produção capitalista. Pode-se abstrair que esse problema social, secularmente engendrado pelo capital, está imerso no mundo do trabalho da lógica neoliberal, lógica essa-considerada como uma fase do capitalismo na contemporaneidade, na qual a produção em massa de mercadorias padronizadas e as formas de trabalho a ela associadas foram substituidas pela flexibilização do trabalho. Aliadas a essa questão estão outras problemáticas, que apontam para a multidimensionalidade da vigência do trabalho em nível planetário, tais como: trabalho e desemprego, trabalho e precarização, trabalho e 
gênero, trabalho e etnia, trabalho e nacionalidade, trabalho e recorte geracional, trabalho e imaterialidade, trabalho e (des)qualificação.

Essas transformações do mundo do trabalho se materializam no cotidiano dos trabalhadores adultos sob a forma de desemprego, precarização das novas formas de produção e das relações de trabalho. Com efeito, essa flexibilização vem, cada vez menos, empregando trabalhadores em tempo integral; isto é, a força de trabalho economicamente ativa, que diuturnamente é solapada em seus direitos. Nesse sentido, percebe-se como o capital é incapaz de realizar sua autovalorização sem se utilizar, de algum modo, do trabalho humano, na medida em que essa lógica estrutural possui em seu âmago a marca destrutiva, obrigando o ser social que trabalha ou "a-classe-que-vive-do-trabalho" (ANTUNES, 1995) e aqueles que estão aptos para o trabalho, mas que não trabalham (CASTEL, 1991) e sequer são exploráveis a vivenciarem o cotidiano de desefetivação do trabalho e suas violências, como a violência do trabalho, a violência da precarização do subemprego e a violência ainda mais grave do desemprego (ANTUNES, 1999).

Na seara desse quadro de exclusão e violência encontra-se a "perversão da exploração do trabalho infantil", expressão cunhada por Neves (1999), isto é, a inclusão precoce e criminosa de crianças no mercado de trabalho, especialmente nos países de industrialização intermediária e subordinada, como, por exemplo, os países asiáticos, latinoamericanos e outros, onde vem se deteriorando prematuramente a força humana de trabalho de crianças e jovens, por meio da exploração visível e invisível, que pode se manifestar na perspectiva da informalidade do mundo do trabalho. Nesse sentido, estamos nos referindo ao trabalho abstrato, cujo objetivo é dispender energias humanas ou trabalho humano e criar mercadorias geradoras de valor.

Em sintese, nessa perspectiva teórica, a exploração do trabalho infantil pode ser inserida na compreensão do trabalho humano em sua dimensão abstrata, ou seja, as crianças são tratadas enquanto mercadorias geradoras de valor (valor de troca), mediante a produção voltada para o mundo das mercadorias, enfim, para a valorização e perpetuação do capital. Nesses termos, as crianças, na contradição, a exemplo dos trabalhadores adultos, não vivenciam, no processo de sua formação humana, o trabalho como símbolo e expressão de criação, felicidade social e atividade vital, mas, sim, como expressão de vivência do martírio, em suma, de servidão. Aliás, o trabalho na lógica neoliberal atual, cada vez mais uberizado e destituído de toda forma de direito e estabilidade, constitui-se um "privilégio da servidão", que, por sua vez, diz respeito ao "espírito do tempo" e da lógica do capital, na qual estamos irrevogavelmente inseridos em meio ao mundo da exploração global do trabalho do humano, de forma fragmentada, precária e perversa, que, ademais, está imersa na "sociedade do trabalho flexível" (ANTUNES, 2018). 
Toda essa dimensão ontológica culmina por negligenciar o projeto de formação humana omnilateral, compreendido como a apropriação do patrimônio cultural pelo individuo no processo de fazer-se membro do gênero humano. Assim, o que nos resta é "[...] buscar o enriquecimento do existir humano em sua omnilateralidade, levando-o necessariamente a assumir a política e ética contra todo modo de vida que imponha obstáculos a esse processo." (DUARTE; DELLA FONTE, 2010, p. 1).

\section{AFINAL, TRABALHO INFANTIL OU EXPLORAÇÃO DO TRABALHO INFANTIL?}

Conforme já mencionamos, a reflexão central deste texto pode ser traduzida na crítica sobre o fenômeno da "exploração do trabalho infantil", e não simplesmente sobre o que se ouve no senso comum a respeito do "trabalho infantil". É fundamental estabelecer essa distinção, pois a exploração do trabalho se circunscreve na perspectiva da alienação e do estranhamento. Essa máxima do capital resulta numa relação alheia do sujeito com objeto (trabalho), coisificando-o, por conseguinte, transformando, aviltando e degradando os homens e o produto do labor em mercadorias. Desse modo, desumaniza o ser social frente ao objeto, em razão da sua imersão numa relação social fundada na propriedade privada e no dinheiro, constituindo-se na abstração da natureza específica e pessoal (ANTUNES, 1995). Isso significa dizer que "L...] o trabalho alienado, ao arrancar o objeto da sua produção, arranca-lhe a sua vida genérica, a sua objetividade genérica efetivamente real e transforma a sua vantagem ante $\circ$ animal na desvantagem de the ter tirado o seu corpo inorgânico, a natureza." (MARX, 1978, p. 147).

Quando se fala simplesmente em "trabalho infantil", pode-se confundi-lo com qualquer tipo de "trabalho de crianças", como, por exemplo, "o trabalho como princípio educativo". Nesse sentido, os princípios axiológicos e teleológicos, do ponto de vista dos pressupostos da teoria marxista, preveem a relação real entre ensino e trabalho, manual e intelectual, visando à formação omnilateral em substituição à formação unilateral das crianças e jovens, tornando-os aptos para alternar as suas atividades de modo a satisfazer tanto as exigências da sociedade quanto as suas inclinações pessoais (MANACORDA, 1991). Essas considerações são fulcrais, considerando que há um senso comum a esse respeito que quase sempre generaliza e banaliza a expressão "trabalho infantil", omitindo o caráter de classe aí contido, além de fazer vistas grossas ao conteúdo da categoria da exploração, do alienus. 
Toda essa confusão de caráter ideológico e epistemológico resulta em dúvidas e equívocos, naturalizando o fenômeno da exploração do trabalho infantil. Assim, traz consequências epistemológicas e políticas, na medida em que mitiga as críticas e as lutas sociais contra o anacronismo destrutivo do modo de produção capitalista. Assim, para complementar esse raciocínio, a simples expressão "trabalho infantil" deve ser reformulada, modificando-se o seu entendimento para "[...] trabalho infantil remunerado, realizado sob condições vis ou penosas por crianças e adolescentes, por isso mesmo interditado pela legislação" (NEVES, 1999, p. 10), mesmo que essa expressão não inclua em suas entrelinhas a categoria da exploração.

Outro ponto importante de ser abordado diz respeito à necessidade de tal diferenciação ser ocultada em grande parte dos documentos do Fundo das Nações Unidas para a Infância (Unicef). Em seu Relatório Situação Mundial da Infância 2003, no qual está implícita a opção pela não radicalização epistemológica da problemática da exploração do trabalho infantil, limita-se a denunciar ou apenas informar sobre os maus-tratos propiciados por "todo o tipo de exploração contra crianças", sem, contudo, problematizar os tipos de exploração e as consequências para a construção da subjetividade e da cidadania infantis. Da mesma forma, os dados estatísticos de vários países, entre os quais destacamos Portugal, utilizam terminologias como "o trabalho por conta de outrem" e escondem o problema da exploração do trabalho infantil (CONDE, 2016). A escolha de termos e palavras não se dá ao acaso, mas expressa uma intencionalidade em velar, pela via da política, o elemento econômico central dessa sociedade: a exploração da mais-valia.

Com efeito, os dados estatísticos sobre a exploração do trabalho infantil são colocados de forma sub-reptícia por esse organismo defensor das causas infantojuvenis no âmbito da seguinte simplificação: "crianças exploradas por adultos". Essa afirmação, além de não nomear o capitalismo como o gestor de todo esse processo histórico de exploração do trabalho de crianças, põe a culpa pelos riscos e a responsabilidade pelos efeitos ameaçadores ao desenvolvimento infantil causados por esse tipo de exploração na sociedade adulta e no comportamento irresponsável dos adultos, ao colocar nesse âmbito o tráfico de crianças para o trabalho escravo e o recrutamento forçado de crianças como soldados para as guerras. Agindo dessa forma, o Unicef presta um serviço em prol do ocultamento desse fenômeno, corroborando para a manutenção do status quo e a confusão epistemológica/ etimológica entre os termos "trabalho infantil" e "exploração do trabalho infantil". Dito dessa forma, não seria nenhum exagero admitir que a repercussão dessa confusão conceitual e ideológica possa incidir sobre a produção de políticas públicas e sociais, cujos respectivos programas e ações governamentais, ditos de "cidadania e inclusão social", na maioria das vezes, estão impregnados de uma lógica precária, emergencial, clientelista e até filantrópica (SILVA, 2007). 
Na esteira dessa reflexão, urge destacar que a exploração do trabalho infantil, fruto da ação destrutiva do capitalismo neoliberal, faz parte do processo de acumulação flexível da globalização da economia e, consecutivamente, da reestruturação produtiva do mundo do trabalho. Todo esse processo é consubstanciado pelos impactos e repercussões sobre as políticas sociais dos países emergentes, por meio das políticas e planos de ajuste estrutural ou cardápios impostos pelo Fundo Monetário Internacional (FMl) e o Banco Mundial. Essas instituições financeiras, gestoras do capital internacional e executoras servis de governos, visam primordialmente - e isso é essencial ao falar de exploração do trabalho de crianças - à desregulamentação do trabalho, à flexibilização, à individualização do contrato de trabalho, à privatização da educação, dos sistemas de saúde e dos serviços públicos, enfim, à destruição da classe trabalhadora (SILVA, 2003). Esse fato político-econômico faz com que a exploração do trabalho infantil persista no âmbito dos governos brasileiros e em outros rincões do Planeta.

Vale lembrar que, além disso, as políticas públicas e sociais de inclusão social e "erradicação do trabalho infantil" desenvolvidas nos Governos de Lula e Dilma, principalmente por meio dos Programas de Erradicação do Trabalho Infantil (PETI), Bolsa Família, Fome Zero, Bolsa Escola e outros, lograram, por um lado, erradicar, provisória e precariamente, a miséria extrema e, consequentemente, o número de crianças trabalhando. Mas, por outro lado, contribuíram para a não radicalização do termo "trabalho infantil", ao invés de "exploração do trabalho infantil" (SILVA, 2007), além de serem limitadas diante da lógica capitalista destruidora e não agirem substancialmente com relação às origens da exploração do trabalho infantil, limitando-se aos seus efeitos aparentes, como, por exemplo, o acesso à renda e à escola.

0 que se pode admitir é que é possível amenizar, reduzir e escamotear temporária e retoricamente o "trabalho infantil" mediante a promessa da ideologia neoliberal, mas nunca como forma de erradicação da exploração, isto é, "arrancando-a pela raiz". Isso não será possível enquanto o ser social estiver sob a regência da servidão sem medidas. Nesse sentido, o marketing da erradicação do trabalho infantil, da miséria, da fome, etc. só terá ressonância quando houver uma radical abolição da propriedade privada, da mais-valia, do trabalho alienado, do trabalho abstrato, da má distribuição de renda e riqueza, da injustiça social e do latifúndio, em suma, da divisão social do trabalho e da exploração, conforme a história de luta do movimento operário expressa densa produção de caráter marxista. A questão colocada traz à tona um mal-entendido, corrente no senso comum e nas hostes acadêmicas, cujo argumento, apressado e generalizado, é de que na teoria marxista há uma posição em favor do trabalho para crianças. Entretanto, essa é uma falsa questão que precisa ser mais bem explicitada. Senão, vejamos o que está expresso, em termos de reivindicação, sobretudo, na Medida n. 1 do Manifesto do Partido Comunista: "[...] Educação Pública e gratuita para todas as crianças. Supressão do trabalho fabril de crianças, tal como praticado hoje. Integração da Educação com a produção material." (REIS FlLH0, 1998, p. 28). 
Na realidade, o que reivindicavam Marx e Engels era o fim da exploração do trabalho das crianças, a abolição da propriedade privada, o aumento da produção e a destruição da divisão social das classes. Portanto, o primordial para eles era o caráter socialista da união entre instrução e o trabalho da fábrica (MANACORDA, 1991). Assim é que principalmente Engels defendia a adoção de medidas aptas a "garantir a existência do proletariado", requerendo todas as suas determinações, quer dizer, não apenas aquelas medidas democráticas referentes à universalidade e à gratuidade do ensino, mas também aquelas medidas referentes à "[...] união entre ensino e trabalho que serão destinadas a todas as crianças e não apenas aos filhos dos proletários." (MANACORDA, 1991, p. 17; NOGUEIRA, 1990, p. 89; SILVA, 2007, p. 57-75). Nesse sentido, para Marx e Engels, era necessário abrir as portas do mundo a todos os educandos, fato esse que já constituía a realidade de boa parte da população: os filhos dos operários. No entanto, tal abertura ao universo do trabalho não deveria ser reduzida à prática pura e simples de um ofício, tampouco a um mero treinamento técnico (aquisição de um saber-fazer ou aprendizagem de um ofício). Assim, eles propunham, na verdade, que a participação das crianças na produção fosse diretamente relacionada à formação intelectual em seu sentido mais amplo.

Essas reflexões abrangem, por conseguinte, o eixo central que os autores tiveram em vista acerca da visão da questão educacional e da formação, baseada na combinação do ensino em todos os níveis - o trabalho produtivo pago para todas as crianças acima de certa idade. Contudo, vale ressaltar que, em Marx, a expressão "trabalho produtivo" é o trabalho que produz mais-valia. Fica claro, então, que Marx e Engels entendiam as atividades de trabalho e de educação como integrantes de um único processo, em que teoria e prática estivessem articuladas, qual seja, a educação politécnica, por meio da qual podem ser transmitidos os princípios gerais e de caráter científico de todo o processo de produção, além de um manejo das ferramentas elementares das diversas profissões. Dessa forma, eles acreditavam que seriam atingidos três objetivos: a intensificação da produção social, a produção de homens omnilaterais, quer dizer, plenamente desenvolvidos, e a obtenção de poderosos meios de transformação da sociedade capitalista (MACHAD0, 1989; SILVA, 2007).

No limiar desse debate, convém destacar que todas as formas de exploração do trabalho infantil podem vir a sonegar ou comprometer o tempo para a vivência da cultura lúdica, comprometendo, consecutivamente, a escolarização e engendrando situações de constrangimentos que repercutem na construção da identidade do ser social criança. Esse visível processo de destruição da infância pode ser considerado como um tempo de oportunidades perdidas, que impõe às crianças possíveis sequelas nutricionais (envelhecimento precoce, desnutrição), cognitivas, psicossociais e culturais, comprometendo de maneira marcante o presente e o futuro de gerações. 
Do ponto de vista da legislação sobre a proibição da exploração do trabalho infantil, há críticas contra a Convenção n. $८ 2$ da Organização Internacional do Trabalho (OIT), editada em 2000, cujo texto, segundo o Tribunal Independente Contra o Trabalho Infantil (SÃO PAUL0, 1999), foi influenciado pelos interesses político-econômicos dos Estados Unidos e por pressões sobre a 0IT, visando à flexibilização da legislação (Convenção 138). Nesse sentido, a nova convenção (182) advoga que devem ser eliminadas apenas as "[...] piores formas de trabalho infantil, não todas as formas de exploração do trabalho infantil." (SILVA, 2007, p. 57-75).

Nessa linha de raciocínio, o livro de Schwartzman (2004), elaborado a partir de dados estatísticos da Pesquisa Nacional de Domicílio (PNAD) e da OIT no Brasil, mostra como a expressão "trabalho infantil" encobre realidades muito distintas, que incluem desde a tradição do trabalho familiar, como a pequena agricultura doméstica desenvolvida nos estados sulinos, que, segundo o autor, não parece afetar as crianças de maneira significativa, até a generalização do trabalho para jovens de 14 a 17 anos. Como se pode perceber, no intuito de fazer críticas à forma como os dados são coletados, interpretados e legitimados pelas estatísticas pública e oficial, o referido autor, apesar de se posicionar contra o trabalho infantil, termina por contribuir para a ideologia embutida na expressão pura e simplista "trabalho infantil" ao deixar de lado a problematização sobre as possiveis relações e diferenciações entre trabalho infantil (trabalho como ajuda, trabalho como princípio educativo) e exploração do trabalho infantil. Também a discussão sobre as piores formas de trabalho infantil e a idade mínima retira o foco da discussão da exploração e prende-se a facetas aparentes do problema. Entendemos que, no capitalismo, toda e qualquer forma de trabalho submete-se à lógica da exploração, e é esse o elemento central a ser discutido e combatido.

Além das produções acadêmicas, há um grande número de publicações de movimentos sociais (em caráter de denúncia das condições de vida deploráveis das crianças e suas familias). Essas publicações apresentam dados estatísticos e relatam os encontros com crianças e pais, com o objetivo de avaliar e sugerir propostas concretas de erradicação do trabalho infantil (reforma agrária, crédito agrícola, educação e saúde). Nas estatísticas dos organismos internacionais sobre a condição da infância empobrecida no mundo, os relatórios da Organização das Nações Unidas para a Educação, a Ciência e a Cultura (Unesco) nos lembram que, na África, cerca de um milhão de crianças morrem a cada ano em consequência do serviço da dívida externa. Não em decorrência de todo um conjunto de reformas, mas sobretudo pelos juros que seus países precisam pagar em termos de dívida externa. Além disso, estima-se que cerca de 11 milhões de crianças morrem todo ano vitimadas por doenças que poderiam ser tratadas facilmente e cujo tratamento não custaria mais do que alguns centavos. No entanto, os economistas informam que isso representaria uma interferência no sistema de livre mercado (CHOMSKY, 1997). 
Os dados estatísticos apresentados no próxima seção deste artigo (FÓRUM NACIONAL DE PREVENÇÃO E ERRADICAÇÃO DO TRABALHO INFANTIL NO BRASIL, 2016) acerca das políticas sociais para a infância e juventude das classes populares apontam para a violência estrutural do capital, que penaliza a classe trabalhadora com a morte de milhões de crianças desnutridas em todo o Planeta. No Brasil, por exemplo, essas crianças empobrecidas correspondem a $53 \%$ das crianças, das quais $19 \%$ vivem no Nordeste e $6 \%$, na região Norte, como indicam os dados do Unicef. Aliás, um grande contingente dessas crianças se assemelha às do sertão alagoano, cuja estrutura corporal é "quase como um peso de um passarinho." (SILVA, 2007).

\section{A PERSISTÊNCIA DO TRABALHO INFANTIL HOJE}

Apesar da proibição do trabalho infantil no Brasil para menores de 16 anos (salvo na condição de aprendiz, entre 14 e 16 anos) e de programas sociais que tentam erradicar o problema, como o PETI e o Bolsa Família, cerca de 1,8 milhão $(5 \%$ da população na faixa etária) de crianças e adolescentes trabalham no País (FÓRUM NACIONAL DE PREVENÇÃO E ERRADICAÇÃO DO TRABALHO INFANTIL NO BRASIL, 2016), o que impacta diretamente na evasão e no abandono escolar. As pesquisas realizadas pela Pesquisa Nacional por Amostra de Domicílio demonstram que, entre 2004 e 2014, houve redução de cerca de $81 \%$ no número de crianças e adolescentes trabalhadores no Brasil. Ainda esse dado seja questionável e não expresse a realidade, o avanço da crise econômica e política no País, bem como com as reduções de investimentos e recursos destinados para a área social, desde 2015 os dados sobre o trabalho infantil voltaram a subir, e os recentes cortes de recursos destinados ao Instituto Brasileiro de Geografia e Estatística não têm possibilitado novas pesquisas sobre a temática. Entretanto, cenas de crianças trabalhando nas ruas voltaram a ser comuns nas cidades brasileiras. Os últimos dados divulgados pelo IBGE evidenciam, também, que o trabalho infantil cresce conforme a idade das crianças. Por volta dos nove anos de idade, um grande número de crianças diminui o tempo de estudos para trabalhar, até que a maioria deixa de estudar para só trabalhar (CONDE, 2012). A maior parte trabalha na agricultura, na pecuária e na silvicultura, seguidas do comércio, serviços gerais, construção civil e trabalho doméstico, em que é mais evidente o trabalho das meninas.

0 agravamento desse quadro, impossível de ser visualizado plenamente em decorrência da ausência de pesquisas recentes pelo IBGE, é acentuado pelo resultado divulgado pelo Instituto Brasileiro de Economia da Fundação Getúlio Vargas. 
Desde 2015, a desigualdade social vem crescendo no Brasil e atingiu, em 2019, o índice de 0,6257. Os dados também mostram que a perda aquisitiva é maior para as populações mais pobres, expressão do aumento do desemprego e das formas uberizadas de contratação da força de trabalho, que, destituída de toda e qualquer forma de direito, se vê ainda mais submetida à exploração no trabalho (FONTES, 2018). Os últimos dados da PNAD evidenciam que a maioria das crianças que trabalham no Brasil estão nos setores da agricultura, pecuária, silvicultura, pesca e aquicultura: 30,8\%. Além disso, "[...] das crianças e adolescentes ocupados no Brasil em 2014, 65,5\% são do sexo masculino e 34,5\% do sexo feminino." (FÓRUM NACIONAL DE PREVENÇÃO E ERRADICAÇÃO DO TRABALHO INFANTIL NO BRASIL, 2016, p. 22). Outra questão interessante a ser pontuada é que os índices de trabalho aumentam proporcionalmente à idade da criança e do adolescente, de forma que é no grupo com idades entre 15 e 17 anos que se encontra a maior "fatia" de indivíduos trabalhadores precoces. Estes dispendem sua força de trabalho predominantemente em atividades urbanas, porém o oposto pode ser verificado entre os mais jovens. Também se destaca o fato de $60 \%$ serem negros ou pardos e $80 \%$ frequentarem a escola, o que evidencia que a escola não dá conta de erradicar o trabalho infantil. Isso não nos surpreende, na medida em que a origem do trabalho infantil não está na escola e, portanto, não seria a escola capaz de resolver o problema. A esmagadora maioria das crianças que trabalham pertencem a familias com renda de até dois salários mínimo, ou seja, o problema da exploração do trabalho infantil tem um recorte de classe, tanto na sua origem quanto na atualidade (CONDE, 2012; PALHOZA, 2019).

\section{CONSIDERAÇÕES FINAIS}

Este artigo evidencia que o problema do trabalho infantil reside no problema da exploração humana inaugurada pela forma capitalista de produção. Políticas sociais e pesquisas nacionais e internacionais abordam a temática sem tocar no elemento fundamental e estruturante da nossa sociedade: a exploração da mais- ${ }^{-}$valia. Assim, prometem erradicar o problema sem atacar suas origens reais. Colocam as crianças na escola, fazem formações com professores, famílias e comunidades, bem como desenvolvem políticas de transferência de renda. Não obstante, o trabalho infantil persiste em sua forma exploradora, conforme mostram os dados do IBGE apresentados neste texto. Como agravante, o aumento da desigualdade social no Brasil e as políticas de austeridade fiscal para o pagamento da inescrupulosa dívida pública apontam para uma tendência de aumento do problema.

0 escamoteamento da palavra "exploração" é parte da estratégia política e discursiva que busca desviar o foco social do elemento central da sociedade capitalista. 
Enquanto o ser social estiver imerso no reino da necessidade e sob a regência da exploração generalizada e da "potência estranha que o domina", como afirmou Marx (1978), não será possível falar em emancipação da condição humana, da infância, da juventude e da velhice da classe trabalhadora. Em outras palavras, sob a forma capitalista, não será possivel que todas as crianças tenham infância.

Embora algumas pesquisas acerca da exploração do trabalho infantil cheguem à conclusão de que, tanto no meio urbano quanto no rural, as crianças, mesmo imersas num quadro de destruição do capital - meio ambiente, direitos dos trabalhadores, da infância, da juventude e da velhice -, brincam em condições adversas de tempo e espaço, muitas vezes em ambientes com esgoto a céu aberto. 0 que realmente está em jogo é o fato de elas brincarem numa realidade destruída pela racionalidade capitalista e, ainda assim, imporemse enquanto seres sociais, resistindo ludicamente, anunciando, enfim, um outro projeto de sociedade. Isso significa dizer que o tempo exíguo para o lúdico também carrega consigo, dialeticamente, as marcas históricas da pobreza, da privação, do trabalho estranhado, do cerceamento, da injustiça e da má distribuição de renda e terra.

Todas as lutas e conquistas em prol da "erradicação do trabalho infantil" só serão possiveis de materializar à luz de políticas sociais estruturadoras: reforma agrária, crédito agrícola, educação pública gratuita e de qualidade, saúde e previdência social; isto, é claro, aliadas à ideia de uma educação para além do capital (MÉZÁROS, 2005). Para Mészáros (2005), a educação não é uma mera transferência de conhecimentos, mas uma forma de libertar o ser humano das cadeias do determinismo neoliberal, levando-se em conta que a história é um campo aberto de possibilidades de lutas, enfrentamentos e superações. Educar para além do capital, portanto, implica pensar uma sociedade para além do capital, isto é, com o fim da exploração generalizada do trabalho de crianças jovens, adultos e velhos (JINKINGS apud MÉZÁROS, 2005).

Por fim, para erradicar a exploração do trabalho infantil e, consecutivamente, de todas as formas de exploração do ser humano, não bastam só críticas aos conceitos e às políticas sociais, às políticas públicas e aos programas e ações do governo. É necessário, em escala nacional e internacional, um conjunto de lutas mais efetivas e radicais por parte de movimentos sociais e sindicais, na perspectiva do enfrentamento ao capital, no que concerne à destruição da propriedade privada dos meios de produção, ao fim do trabalho abstrato e em prol do direito ao trabalho concreto, portanto, ao trabalho enquanto centralidade do ser social e à capacidade de transformar-se a si próprio, o mundo, a natureza e a sociedade e o nosso semelhante.

\section{REFERÊNCIAS}


ANTUNES, R. Adeus ao trabalho. Campinas: Editora da Unicamp, 1995.

ANTUNES, R. Os sentidos do trabalho: ensaio sobre a afirmação e a negação do Trabalho. São Paulo: Boitempo, 1999.

ANTUNES, R. 0 privilégio da servidão: o novo proletariado de serviços na era digital. São Paulo: Boitempo, 2018.

CASTEL, R. et al. Da indigência à exclusão, a desfiliação: precariedade do trabalho e vulnerabilidade relacional. In: DONZELOT, J. (org.). Face a L"exclusion: le modèle Français. Paris: Esprit, 1991. p. 137-168.

CHOMSKY, N. Segredos, mentiras e democracia. Brasília: Ed. UNB, 1997.

CONDE, S. F. Quando o trabalho infantil se torna uma generalidade social. Revista Trabalho Necessário, v. 10, n. 15, p. 1-22, 2012.

CONDE, S. F. A escola e a exploração do trabalho infantil na fumicultura catarinense. Florianópolis: Editora Em Debate, 2016.

DUARTE, N.; DELLA FONTE, S. S. Arte, conhecimento e paixão na formação humana. Campinas: Autores Associados, 2010.

FONTES, V. Capitalismo em tempos de uberização: do trabalho ao emprego. Marx e o Marxismo, Rio de Janeiro, v. 5, n. 8, p. 45-67, jan./jun. 2018. Disponível em: https://bit.ly/2m5lmkj. Acesso em: 20 ago. 2018.

FÓRUM NACIONAL DE PREVENÇÃO E ERRADICAÇÃO DO TRABALHO INFANTIL NO BRASIL. 0 trabalho infantil nos principais agrupamentos de atividades econômicas do Brasil. Brasília, DF: FNPETI, 2016. Disponivel em: https://fnpetiorg.br/media/12dejunho/documentos-de-referencia/0_Trabalho_Infantil_nos_Principais_Grupamentos_de_Ati.pdf. Acesso em: $16 \mathrm{dez} .2019$.

HOBSBAWN, E. J. A Era das Revoluções. São Paulo: Paz e Terra, 2007.

MACHADO, L. R. de S. Politécnica, escola unitária e trabalho. São Paulo: Cortez, 1989.

MANACORDA, M. A. Marx e a pedagogia moderna. São Paulo: Cortez, 1991.

MARX, K. Manuscritos econômico-filosóficos e outros textos escolhidos. São Paulo: Abril Cultural, 1978.

MARX, K. 0 Capital: crítica da economia política. 3. ed. São Paulo: Nova Cultural, 1988.

MARX, K. Trabalho assalariado e capital. 5 de abril de 1849. Lisboa: Editora Avante, 2006. Tomos I, II e III. (Obras Escolhidas).

MÉSZÁROS, I. A educação para além do capital. São Paulo. Boitempo: 2005. 
NEVES, D. P. A perversão do trabalho infantil. Niterói: Intertexto, 1999.

NOGUEIRA, M. A. Educação, saber, produção em Marx e Engels. São Paulo: Cortez, 1990.

PALHOZA, N. Nada de novo sob o parreiral: o trabalho infantil dos ítalo-descendentes na vitivinicultura videirense. 2019. Dissertação (Mestrado em Educação) - Universidade Federal de Santa Catarina, Florianópolis, 2019.

REIS FLLHO, D. 0 Manifesto do Partido Comunista 150 anos depois. Rio de janeiro: Contraponto, 1998.

RUBIN, I. L. A Teoria Marxista de Valor. São Paulo: Ed. Polis, 1987.

SÃO PAULO (Estado). Tribunal Internacional Contra o Trabalho Infantil. Sentença. São Paulo, 1999. Mimeo.

SCHWARTZMAN, Simon. As causas da pobreza. Rio de Janeiro: FGV, 2004.

SILVA, M. R. Trama doce-amarga: (exploração do) trabalho infantil e cultura lúdica. São Paulo: Hucitec; ljuí: Unijuí, 2003.

SILVA, M. R.; Trabalho infantil ou exploração do trabalho infantil. In: REDIN, E.; MÜLLER, F.; REDIN, M. M. (org.). Infâncias: cidades e escolas amigas das crianças. Porto Alegre: Mediação, 2007. p. 57-75.

THOMPSON, E. P. A formação da classe operária inglesa II (A maldição de Adão). São Paulo: Paz e Terra, 2002.

Endereço para correspondência: Campus Universitário Reitor João David Ferreira Lima, Trindade Florianópolis, Santa Catarina, Brasil; sorayafconde@gmail.com

Roteiro, Joaçaba, v. 45, p. 1-20, jan./dez. 2020 I e23071 IE ISSN 2177-6059 